\title{
Bone Marrow Transplantation
}

\author{
K. Ananda Krishna and K.R.S. Sambasiva Rao*
}

Center for Biotechnology, Acharya Nagarjuna University, Guntur 522 510, AP, India

\begin{abstract}
Stem cells are the centre for regenerative medicine. Given a right signal these undifferentiated cells have a remarkable potential to develop into specialized cell types (blood cells, heart cells etc.) in the human body. Stem cells, therefore, can be used in cell-based therapies to replace/repair damaged tissues and/or organs. Ongoing research in the area of stem cells focuses on their potential application (both embryonic stem cells and adult stem cells) to create specialized cells and replace the damaged ones. Hence, this cutting-edge technology might lead to new ways of detecting and treating diseases. Stem cell transplantation can be considered as an option for the treatment of certain type of cancers. This medical procedure can also be used to treat neurological diseases, autoimmune diseases, heart diseases, liver diseases, metabolic disorders, spinal cord injury etc. The present review, therefore, focuses on the growing use of stem cell transplantation in regenerative medicine to treat a variety of diseases. This review also provides the current status of the field with a particular emphasis on bone marrow transplantation.
\end{abstract}

Key Words: Bone marrow, leukemia, multiple myeloma, Parkinson's disease, stem cell, transplantation.

\section{INTRODUCTION}

Two Canadian researchers from the Ontario Cancer Institute, Ernest A. McCulloch and James E. Till (early 1960s) were the first to show the existence of self-renewing stem cells in the mouse bone marrow [1-3]. Their landmark studies revealed the properties of stem cells: (i) self-renewal capacity and (ii) ability to undergo differentiation pathways [4]. They laid foundation for the stem cell research. Since then stem cell research has opened doors for a new therapeutic avenue to explore regenerative medicine and treat myriad diseases. In 1968 an American physician, Robert A. Good performed the first successful human bone marrow transplants (using human leukocyte antigen-identical siblings) by treating an 8-year-old boy with severe combined immunodeficiency syndrome [5]. Now-a-days, bone marrow transplant is the commonest and best-known type of transplant $[6,7]$. In bone marrow transplantation a patient receives healthy bone marrow that contains stem cells with the capacity to mature into specialized cells. A transplant procedure restores stem cells after the administration of high-dose chemotherapy and/or radiation therapy. In addition, peripheral blood stem cell transplants are more common $[8,9]$. This type of transplant is increasing and has nearly replaced bone marrow transplantation. For instance, a systematic review showed the use of peripheral blood stem cells to speed the engraftment of neutrophil and platelets compared to the standard bone marrow transplant [10]. Umbilical cord blood stem cell transplants, however, are considered an alternate option because they are less prone to rejection [11]. In a systematic review and meta-analysis, Hwang et al. [12] showed that despite greater donor-recipient human leukocyte antigen disparity with unrelated donor cord blood transplant, this

*Address correspondence to this author at the Center for Biotechnology, Acharya Nagarjuna University, Guntur 522 510, AP, India; Tel: +91 0863 2293400; Fax: +91 0863 2293378; E-mail: krssrao@gmail.com type of transplant in children and adults had consistently equivalent survival outcomes compared to unrelated donor bone marrow transplant. In addition, studies have shown that the graft-versus-host disease after cord blood transplant is less compared to bone marrow transplant or peripheral blood transplant. However, long time for engraftment, higher risk of infection, and availability of backup cells are some of the major hurdles to overcome for a successful transplant. To make more cells available, cord blood is stored in a facility known as 'cord blood bank'. After the baby is born, the cord blood is collected from the umbilical cord and placenta by a process that poses minimal health risk. (For type of transplants based on stem cell source see Table 1).

Thus, over time there is advancement in identifying various sources of stem cells for the purpose of transplant and evaluating the effectiveness of transplant. Researchers are currently working on stem cells (embryonic and adult stem cells) from both animals and human beings. They believe that stem cells are the best candidates for regenerative medicine. However, the questions regarding reasons for the stem cells to exist in undifferentiated state and signals required for demonstrating their plasticity need to be addressed.

\section{STEM CELL TRANSPLANT}

Stem cell transplants are routinely used medical procedures to treat various diseases. These transplants are further categorized (based on the donor) into (i) autologous stem cell transplants (autografts) - patients receive their own stem cells, (ii) allogeneic stem cell transplants (allografts) - patients receive stem cells from their family member or a genetically similar individual, (iii) syngeneic stem cell transplants - patients receive stem cells from their identical twin, (iv) tandem autologous transplants (double autologous transplants) - a patient receives two planned transplants within a short period, and (v) mini allogeneic transplants (nonmyelo- 
Table 1. Types of Stem Cell Transplants Based on Source

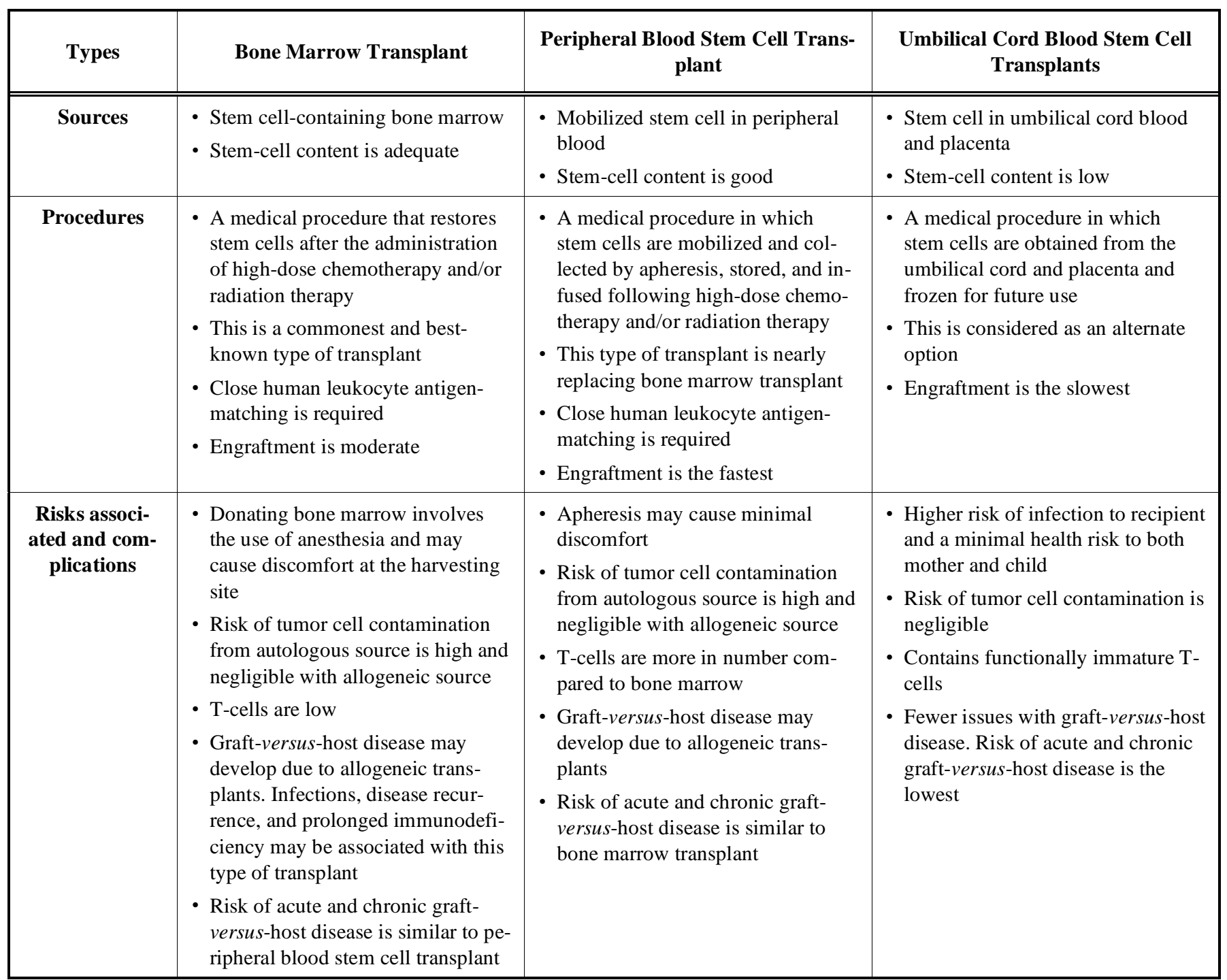

ablative) - lower doses of chemotherapy/radiation are used, ensuring bone marrow is not completely destroy [13-17]. The process of stem cell transplantation is complex. Autologous and allograft procedures are almost similar, involving harvesting of bone marrow or peripheral blood, processing and cryopreservation (autologous transplants alone), transplantation of stem cells after conditioning (chemotherapy or chemoradiotherapy), engraftment and recovery [18].

Bone marrow aspiration (bone marrow tap; See Fig. (1)) involves the removal of a small amount of bone marrow fluid and cells through a needle. This process is similar in autologous, syngeneic, and allogeneic stem cell transplants. The donor receives anesthesia, and a needle is inserted into the skin over the pelvic bone or sternum until it reaches the bone to draw a small amount of bone marrow fluid. As the time progresses this fluid is replaced by the donor's body; however, the risk associated involves the use of anesthesia. The donor may recover within a few days or weeks. Later, the bone marrow is processed to remove blood and bone fragments. The harvested bone marrow is combined with a preservative and cryopreserved for further use. Two applica- tions of the bone marrow transplant include diagnosing a disease and monitoring response to therapy. During bone marrow transplant stem cells are procured by direct puncture and aspiration of bone marrow, filtered, and reinfused intravenously [7]. However, stem cells derived from the bone marrow can be liberated into the peripheral blood and harvested with a cell separation machine. Similar to bone marrow transplant, peripheral blood stem cell transplant is an autologous transplant procedure in which the stem cells are collected from patient's blood. The blood passes through a machine that removes stem cells and the blood is returned a procedure called apheresis. This procedure can be performed along with an autologous bone marrow transplant. Both procedures are used to restore stem cells that are destroyed during high-dose chemotherapy and/or radiation therapy. The advantages with autologous peripheral blood stem cell transplants over bone marrow autografts are faster recovery, lesser morbidity due to transplant, shorter hospital stay and reduced cost. In addition, the peripheral blood stem cell transplantation requires no general anesthesia and engraftment is rapid with earlier discharge from hospital [7]. 
The application of other transplant procedures is discussed in the latter sections.

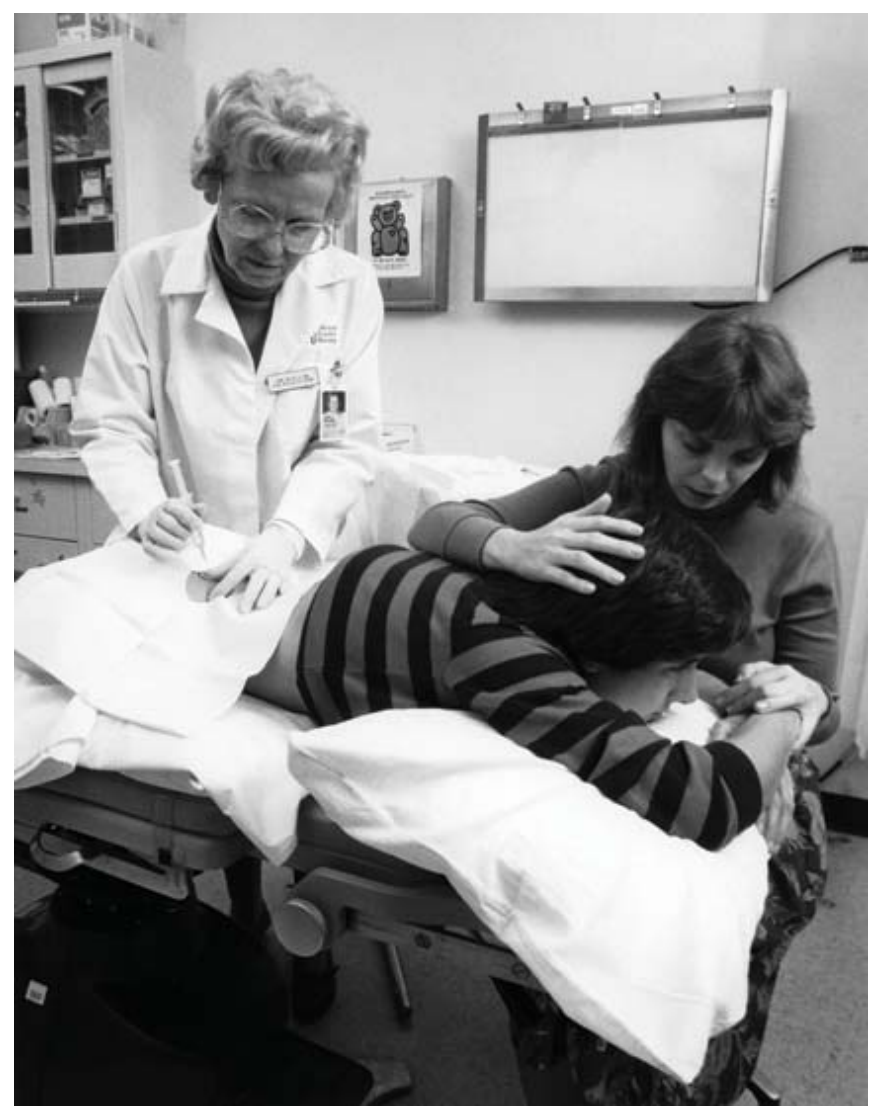

Fig. (1). Picture of patient on examining table getting needle inserted for a bone marrow tap. Mother shown with patient [Source: National Cancer Institute. Author: Bill Branson (Photographer)].

Now-a-days, stem cell transplant is rapidly evolving, enabling the translation into clinical applications. In the future, advancement in transplant procedures may be more promising. Trials are on the way to treat various diseases. Stem cell transplant is considered as an option for the treatment of certain type of cancers [19]. This medical procedure can also be used to treat neurological diseases [20], autoimmune diseases [21], restoration of sight [22], wound healing [23], heart diseases [24], liver diseases [25], metabolic disorders [26], spinal cord injury [27] etc. The present review, therefore, focuses on the growing use of stem cell transplantation in regenerative medicine to treat a variety of diseases. This review also provides the current status of the field with a particular emphasis on bone marrow transplantation.

\subsection{Stem Cell Transplant for the Treatment of Certain Type of Cancers}

Stem cell transplant is used to treat various types of cancers. Initially, blood cancers like leukemia, lymphoma, and myeloma are treated with chemotherapy and/or radiation therapy. Prior to these therapies stem cells are collected from a donor and the cells are later infused/reinfused into a patient. These cells thereby replace the destroyed ones. Thus, stem cell transplant performed after chemotherapy and/or radiation therapy restores the damaged cells.

\subsubsection{Leukemia: A Cancer of Bone Marrow and Lympho- cytes}

In the past decade there has been enormous development in the treatment of leukemia. Leukemia affects lymphoid cells (lymphocytic leukemia) or myeloid cells (myeloid or myelogenous leukemia). Acute lymphoblastic leukemia, acute myelogenous leukemia, chronic lymphocytic leukemia, and chronic myelogenous leukemia are the commonest type of leukaemias. In 2008 an estimated 44,270 men and women will be diagnosed with leukemia, and the mortality due to leukemia will be 21,710 in both men and women [28] (Surveillance, Epidemiology and End Results). In the US alone (2005) about 220,063 men and women alive had a history of leukemia. Various trials were conducted to cure patients with leukemia. A meta-analysis of seven studies (1274 patients) showed that allogeneic hematopoietic stem cell transplant improves the outcome of patients with high-risk adult acute lymphoblastic leukemia [29]. Results from two trials, ALLBerlin-Frankfurt-Münster 90 and ALL-Berlin-FrankfurtMünster 95 revealed that stem cell transplant in first complete remission is superior to the treatment with chemotherapy alone for childhood high-risk T-cell acute lymphoblastic leukemia [30]. Ciceri et al. [31] analyzed 173 adults with acute myeloid leukemia and 93 with acute lymphoblastic leukemia who received haploidentical hematopoietic stem cell transplantation (Europe). Their study results showed that this transplantation is an alternative for the treatment of high-risk acute leukemia patients in remission, lacking a human leukocyte antigen-matched donor. A retrospective analysis of data from 58 adult Japanese patients (51 with acute myeloid leukemia and 7 with acute lymphoblastic leukemia) suggested that treatment strategies including allogeneic hematopoietic stem cell transplantation may be considered in the first complete response in acute myeloid leukemia patients with $11 \mathrm{q} 23$ abnormalities [32]. Hah et al. [33] showed (in a 15-year-old girl) that chemotherapy and autologous peripheral blood stem cell transplant seems to be potentially effective for multiple recurrent anaplastic oligodendroglioma occurring after childhood acute lymphoblastic leukemia. In a retrospective study (97 adult), Mohty et al. [34] demonstrated that reduced-intensity conditioning allogeneic stem cell transplantation is feasible in patients with high-risk lymphoblastic leukemia in remission at transplantation. Hayani et al. [35] showed the first report of autologous umbilical cord blood transplantation in the treatment of a 3-year-old girl with acute lymphoblastic leukemia. Results of the prospective Cord Blood Transplantation showed that umbilical cord blood transplantation in adults should be performed in specialized centers [36]. Bradstock et al. [37] demonstrated that unrelated cord blood transplant is feasible in adults with high-risk malignancy, with infection relating to immunocompromise being the major limitation. A report from the International Bone Marrow Transplant Registry and the European Group for Blood and Marrow Transplantation showed that leukemia-free survival rates were higher after peripheral blood stem cell transplant $(33 \%)$ compared to bone marrow transplant $(25 \%)$ in advanced chronic myeloid leukemia patients, but were lower for those in first chronic phase $(41 \%$ vs. $61 \%)$; however, these rates were similar for acute leukemia [38]. In a retrospective comparison, Lemoli et al. [39] showed that allogeneic peripheral blood stem cell transplant performed in the early stage of the 
disease is safe and may be associated with a more rapid hematopoietic reconstitution compared to the bone marrow transplant. A report from the cooperative German Transplant Study Group revealed that allogeneic stem cell transplant in elderly (aged >50 years) with standard- or high-risk acute myeloid leukemia, donor type is not a major prognostic factor [40]. A retrospective, multicenter study of 63 children (aged 0.2-17 years) showed that allogeneic hematopoietic stem cell transplantation was able to rescue a significant proportion of children with acute myeloid leukemia in second complete remission - especially if a human leukocyte antigen-compatible relative is a donor [41]. In a case representing dispermic chimerism in a 32-year-old man diagnosed with acute myelomonocytic leukemia, Draper et al. [42] showed that molecular human leukocyte antigen typing is required to reduce transplant rejection in such patients. Majhail et al. [43] demonstrated that human leukocyte antigen mismatched umbilical cord blood is an alternative graft source for elderly who need a transplant but do not have a matched related donor. In a retrospective analyses, the results of 32 (11 autologous, 21 allogeneic) hematopoietic stem cell transplants showed that both type of transplants were effective in the treatment of children with relapsed or refractory acute promyelocytic leukemia [44]. In a retrospective multicenter study (73 patients; SFGM-TC) reducedintensity conditioning allogeneic stem cell transplantation in advanced chemosensitive disease lead to a long-term survival despite associated with significant transplant-related mortality [45]. Results of the prospective multicenter LALA94 study revealed that allogeneic stem cell transplant should be offered in first complete response to $t(1 ; 19) / E 2 A-P B X 1$ or $\mathrm{t}(4 ; 11) / \mathrm{MLL}-\mathrm{AF} 4$ patients [46]. In a randomized prospective study of 30 patients with different hematological diseases (acute myeloid leukemia, acute lymphoblastic leukemia, chronic myeloid leukemia, myelodysplastic syndrome or severe aplastic anemia), Mahmoud et al. [47] showed that peripheral blood stem cell transplant is associated with faster hematopoietic recovery and the incidence of acute graftversus-host disease does not exceed that observed with bone marrow transplantation. In a randomized trial of allogeneic related bone marrow transplant (40 patients) compared to peripheral blood stem cell transplant (32 patients) for chronic myeloid leukemia, a higher cumulative incidence of relapse (at 3 years) was observed in those who underwent bone marrow transplantation (7\% vs. 0\%) [48]. In the BGMT 87 study, Reiffers et al. [49] compared allogeneic bone marrow transplant, autologous stem cell transplant and chemotherapy in patients with acute myeloid leukemia in the first remission. There was no statistical difference between autologous stem cell transplant and chemotherapy for either disease-free survival, risk of relapse or survival, indicating that allogeneic bone marrow transplant may at least produce superior results. Furthermore, alternative source of stem cell for the purpose of transplant need to be explored, factor effecting transplant need to be identified, transplant techniques need to be further explored, transplant procedure must be performed in specialized centers, rejection due to transplant and incidence of acute graft-versus-host disease must be reduced.

\subsubsection{Multiple Myeloma: A Cancer of Plasma Cells}

Multiple myeloma [50] accounts for $0.8 \%$ of all cancers worldwide with approximately 86,000 new cases per year
[51]. This malignant disease is characterized by the accumulation of monoclonal plasma cells in the bone marrow and the secretion of paraprotein. Plasma cells are important components of immune system involved in the production of special chemicals called immunoglobulins (combat infectious agents). Conversely, malignant plasma cells produce abnormal immunoglobulins (monoclonal protein or paraproteins). Currently, various options for the treatment of multiple myeloma include radiation therapy, conventional and high-dose chemotherapy, autologous and allogeneic stem cell transplantation, and immunotherapy. Clinical trials, however, have shown that autologous stem cell transplantation is superior to conventional dose therapy in the treatment of multiple myeloma patients. Yet, no complete cure exists for this disease. Currently, the median overall survival of multiple myeloma patients after stem cell transplantation and targeted therapies is nearly 5 years, however those treated with conventional chemotherapy survived for more than 10 years. Therefore there is necessary to know the potentially favorable prognostic factors for the selection of targeted treatments [52]. Two meta-analyses on high-dose therapy and autologous stem cell transplantation in frontline multiple myeloma indicated highly significant associations between maximal response during or after high-dose therapy and autologous stem cell transplantation and long-term outcomes. Both meta-analyses provided evidence of highly significant associations between maximal response following induction therapy and long-term outcomes [53]. Allogeneic bone marrow transplantation using human leukocyte antigenmatched sibling donors appeared to be a promising method of treatment for some patients with multiple myeloma [54]. In a prospective, randomized trial, patients with multiple myeloma (under the age of 65 years) were randomly assigned to receive either conventional chemotherapy or highdose therapy and autologous bone marrow transplantation. Intergroupe Francophone du Myélome 90 trial (200 patients) compared conventional-dose chemotherapy to autologous bone marrow transplant. The results showed that high-dose therapy combined with transplantation improved the response rate and progression-free and overall survival rates [55]. The 5-year rate of survival was 52\% in the high-dose group and $12 \%$ in the conventional-dose group. In a Medical Research Council Myeloma VII trial (401 patients), patients with previously untreated multiple myeloma (aged <65 years) received either standard conventional-dose combination chemotherapy or high-dose therapy and an autologous stem cell transplant. The high-dose therapy with autologous stem cell rescue was an effective first-line treatment. The transplant provided superior progression-free survival and overall survival, and the median survival for transplant compared to chemotherapy was 54 months vs. 42 months, respectively [56]. In Intergroupe Francophone du Myélome 94 trial (399 patients), double autologous stem cell transplantation improved overall survival among patients with multiple myeloma compared to those who underwent a single autologous stem cell transplantation after a high-dose chemotherapy [57]. The double transplantation provided superior event-free survival and overall survival. The 7-year survival was with $42 \%$ and $21 \%$ with double transplant and single transplant, respectively. In a prospective, randomized study of comparing single versus double autologous stem cell transplant (Bologna 96 trial; 200 patients), Cavo et al. [58] 
showed that double autologous stem cell transplant effects superior complete response or near complete response rate, relapse-free survival, and event-free survival, but failed to significantly prolong overall survival. The median survival was 60 and 50 months with the double transplant and single transplant, respectively. Altogether autologous stem cell transplant improves the median survival time and is considered as the standard of care for younger patients, however, questions regarding the management of myeloma need to be addressed. Studies have shown that peripheral blood stem cells can also be used as an alternate source of stem cell transplant because they are easily available and they reduce transplant-related toxicity [59]. The results of such studies are encouraging. Recently, an evidence-based practice guideline assessing the role of stem cell transplant in patients with multiple myeloma was developed. This guideline comprises six recommendations. This guideline recommends autologous transplant for patients with stage II or III myeloma and good performance status, whereas allogeneic transplantation is not recommended as a routine therapy [60]. In the future, stem cell transplantation in combination with novel drugs might provide cure for patients with multiple myeloma. In addition, achieving complete response will be the first step forward toward cure for those with multiple myeloma.

\section{DISCUSSION}

Bone marrow transplant is a promising strategy for the treatment of various diseases. The key for a successful bone marrow transplant involves matching for the human leukocyte antigen system between donor and recipient and the migration of stem cells to find proper niche, expand and differentiate without depletion of the stem cell pool. Bone marrow (medulla ossea) [61] is a soft blood-forming tissue that contains hematopoietic, mesenchymal, and endothelial stem cells. Hematopoietic stem cells have the capability to differentiate into mature cell types of blood (give rise to leukocytes, erythrocytes, thrombocytes) and these cells can be used for successful transplant, whereas mesenchymal stem cells have the capability to differentiate into other cell types. Apart from the hematopoietic stem cells, umbilical cord blood stem cells can be used as an alternative source for transplant [62]. The advantage of using bone marrow for transplant is faster engraftment, whereas the disadvantages are lack of donor, longer search times, more graft-versushost disease. Conversely, the use of umbilical cord blood has faster availability, rapid donor identification, decreased transmission of viral diseases, reduced graft-versus-host disease, and ease of scheduling transplant [63].

Bone marrow and peripheral blood stem cell transplants are used in the treatment of certain type of cancers, making it possible for patients to receive a high-dose chemotherapy and/or radiation therapy. Peripheral blood stem cell transplant, however, requires no general anesthesia and engraftment is rapid with earlier discharge from hospital [7]. Stem cell transplants, however, are associated with complications - as the allogeneic bone marrow and peripheral blood transplants are associated with graft-versus-host disease. While performing allogeneic stem cell transplant, the transplanted cells must closely match that of host, which is determined by the human leukocyte-associated antigens (surface proteins of cells). An individual has three pairs of major human leukocyte-associated antigens: human leukocyte antigen-A, human leukocyte antigen-B, and human leukocyte antigen-DR. The complication associated with post-allogeneic bone marrow transplant is graft-versus-host disease and autoimmune-like disorders. The successful transplant largely depends on the higher number of matches of human leukocyte-associated antigen tissue types between donor and recipient. And the patient is less likely to develop a common side effect known as graft-versus-host disease. Here, the immune cells of the host in the transplanted marrow recognize the patient as foreign and strikes an immunologic attack. This is prevented when the patient receives medications to suppress immune system. Human leukocyte-associated antigen matching is more likely in close relatives compared to unrelated donor; however, identical twins have same set of human leukocyteassociated antigens and syngeneic transplant is rare.

Research is more inclined toward decreasing graftversus-host disease, overcoming the human leukocyte antigen histocompatability barriers. Efforts are to reduce transplant-related mortality. Conversely, umbilical cord blood (rich in hematopoietic stem cells) is successfully used as an alternative source of transplant. Currently, bone marrow transplant is used to treat acute myelogenous leukemia, acute lymphocytic leukemia, chronic lymphocytic leukemia, chronic myelogenous leukemia, myeloproliferative disorders, multiple myeloma, non-Hodgkin lymphoma, Hodgkin disease, breast cancer, testicular cancer, ovarian cancer, glioma, neuroblastoma, small-cell lung cancer, non-smallcell lung cancer, severe aplastic anemia, $\beta$-Thalassemia, severe combined immunodeficiency, autoimmune disorders, amyloidosis, and hereditary metabolic disorders. In future, the advancement in these transplant procedures may hold potential to restore the function of damaged heart and regenerate damaged nervous tissue. These medical procedures may also be used to treat Alzheimer's disease, diabetes, liver disease, muscular dystrophy, Parkinson's disease, and spinal cord injury. For instance, Parkinson's and Huntington's [64] are the commonest neurodegenerative diseases that lead to the deterioration of neurons. These diseases are a major global health problem. Understanding the cause and identifying the novel pathways may help find interesting clues to unlock the mysteries. Although there is little possibility for brain cells to regenerate, preclinical studies using various stem cells have shown that they raise a new hope to repair and replace the destroyed brain tissue. Thus, seeking for therapeutic options like the application of stem cells for the treatment of human neurodegenerative disorders may sound very interesting; however, there are various hurdles to overcome. The human neural stem cells may be cultured, genetically modified, and transplanted to restore normal function of the brain. Currently, scientists are attempting to use stem cells to make dopamine producing neurons. Stem cells might one day be programmedable to replace the dead cells with healthy ones - providing a step forward in stem-cell based treatment for Parkinson's disease.

\section{REFERENCES}

[1] Till JE, McCulloch EA. A direct measurement of the radiation sensitivity of normal mouse bone marrow cells. Radiat Res 1961; 14: 213-22.

[2] Becker AJ, McCulloch EA, Till JE. Cytological demonstration of the clonal nature of spleen colonies derived from transplanted mouse marrow cells. Nature 1963; 197: 452-4. 
[3] Siminovitch L, McCulloch EA, Till JE. The distribution of colonyforming cells among spleen colonies. J Cell Physiol 1963; 62: 32736.

[4] McCulloch EA, Till JE. Perspectives on the properties of stem cells. Nat Med 2005; 11: 1026-8.

[5] Gatti RA, Meuwissen HJ, Allen HD, Hong R, Good RA. Immunological reconstitution of sex-linked lymphopenic immunological deficiency. Lancet 1968; 2: 1366-9.

[6] Ikehara S. Bone marrow transplantation: a new strategy for intractable diseases. Drugs Today (Barc) 2002; 38: 103-11.

[7] Duncombe A. ABC of clinical haematology: Bone marrow and stem cell transplantation. BMJ 1997; 314: 1179.

[8] Hénon PR. Peripheral blood stem cell transplantation: critical review. Int J Artif Organs 1993; 16: 64-70.

[9] Watanabe T, Takaue Y, Kawano Y. Peripheral blood stem cell transplantation; an update. J Med Invest 1997; 44: 25-31.

[10] Lewis A. Autologous stem cells derived from the peripheral blood compared to standard bone marrow transplant; time to engraftment: a systematic review. Int J Nurs Stud 2005; 42: 589-96.

[11] Gluckman E, Rocha V, Chevret S. Results of unrelated umbilical cord blood hematopoietic stem cell transplantation. Rev Clin Exp Hematol 2001; 5: 87-99.

[12] Hwang WY, Samuel M, Tan D, Koh LP, Lim W, Linn YC. A meta-analysis of unrelated donor umbilical cord blood transplantation versus unrelated donor bone marrow transplantation in adult and pediatric patients. Biol Blood Marrow Transplant 2007; 13: 444-53.

[13] Saba N, Abraham R, Keating A. Overview of autologous stem cell transplantation. Crit Rev Oncol Hematol 2000; 36: 27-48.

[14] Bosi A, Bartolozzi B, Guidi S. Allogeneic stem cell transplantation. Transplant Proc 2005; 37: 2667-9.

[15] Worel N, Biener D, Kalhs P, et al. Long-term outcome and quality of life of patients who are alive and in complete remission more than two years after allogeneic and syngeneic stem cell transplantation. Bone Marrow Transplant 2002; 30: 619-26.

[16] Rosiñol L, Pérez-Simón JA, Sureda A, et al. Programa para el Estudio y la Terapéutica de las Hemopatías Malignas y Grupo Español de Mieloma (PETHEMA/GEM). A prospective PETHEMA study of tandem autologous transplantation versus autograft followed by reduced-intensity conditioning allogeneic transplantation in newly diagnosed multiple myeloma. Blood 2008; 112: 3591-3

[17] Maloney DG, Sandmaier BM, Mackinnon S, Shizuru JA. Nonmyeloablative transplantation. Hematology Am Soc Hematol Educ Program 2002; 1: 92-421.

[18] Lennard AL, Jackson GH. Science, medicine, and the future: Stem cell transplantation. BMJ 2000; 321: 433-7.

[19] Sagar J, Chaib B, Sales K, Winslet M, Seifalian A. Role of stem cells in cancer therapy and cancer stem cells: a review. Cancer Cell Int 2007; $7: 9$.

[20] Hess DC, Borlongan CV. Stem cells and neurological diseases. Cell Prolif 2008; 41: 94-114.

[21] van Laar JM, Tyndall A. Adult stem cells in the treatment of autoimmune diseases. Rheumatology (Oxford) 2006; 45: 1187-93.

[22] Pellegrini G, De Luca M, Arsenijevic Y. Towards therapeutic application of ocular stem cells. Semin Cell Dev Biol 2007; 18: 80518.

[23] Cha J, Falanga V. Stem cells in cutaneous wound healing. Clin Dermatol 2007; 25: 73-8.

[24] Strauer BE, Brehm M, Schannwell CM. The therapeutic potential of stem cells in heart disease. Cell Prolif 2008; 41: 126-45.

[25] Wang Z, Lu H, Wang YC, Cong XQ. Human embryonic stem cells and liver diseases: from basic research to future clinical application. J Dig Dis 2008; 9: 14-19.

[26] Schulze M, Fändrich F, Ungefroren H, Kremer B. Adult stem cellsperspectives in treatment of metabolic diseases. Acta Gastroenterol Belg 2005; 68: 461-65.

[27] Coutts M, Keirstead HS. Stem cells for the treatment of spinal cord injury. Exp Neurol 2008; 209: 368-77.

[28] Surveillance, Epidemiology and End Results. Available at seer.cancer.gov/

[29] Yanada M, Matsuo K, Suzuki T, Naoe T. Allogeneic hematopoietic stem cell transplantation as part of postremission therapy improves survival for adult patients with high-risk acute lymphoblastic leukemia: a metaanalysis. Cancer 2006; 106: 2657-63.
[30] Schrauder A, Reiter A, Gadner H, et al. Superiority of allogeneic hematopoietic stem-cell transplantation compared with chemotherapy alone in high-risk childhood T-cell acute lymphoblastic leukemia: results from ALL-BFM 90 and 95. J Clin Oncol 2006; 24: 5742-9.

[31] Ciceri F, Labopin M, Aversa F, et al. Acute Leukemia Working Party (ALWP) of European Blood and Marrow Transplant (EBMT) Group. A survey of fully haploidentical hematopoietic stem cell transplantation in adults with high-risk acute leukemia: a risk factor analysis of outcomes for patients in remission at transplantation. Blood 2008; 112: 3574-81.

[32] Tamai H, Yamaguchi H, Hamaguchi H, et al. Clinical features of adult acute leukemia with $11 \mathrm{q} 23$ abnormalities in Japan: a cooperative multicenter study. Int J Hematol 2008; 87: 195-202.

[33] Hah JO. Anaplastic oligodendroglioma after childhood acute lymphoblastic leukemia: chemotherapy and autologous peripheral blood stem cell transplantation. J Pediatr Hematol Oncol 2008; 30: 764-7.

[34] Mohty M, Labopin M, Tabrizzi R, et al. Acute Leukemia Working Party; European Group for Blood and Marrow Transplantation. Reduced intensity conditioning allogeneic stem cell transplantation for adult patients with acute lymphoblastic leukemia: a retrospective study from the European Group for Blood and Marrow Transplantation. Haematologica 2008; 93: 303-6.

[35] Hayani A, Lampeter E, Viswanatha D, Morgan D, Salvi SN. First report of autologous cord blood transplantation in the treatment of a child with leukemia. Pediatrics 2007; 119: 296-300.

[36] Cornetta K, Laughlin M, Carter S, et al. Umbilical cord blood transplantation in adults: results of the prospective Cord Blood Transplantation (COBLT). Biol Blood Marrow Transplant 2005; 11: $149-60$.

[37] Bradstock KF, Hertzberg MS, Kerridge IH, et al. Unrelated umbilical cord blood transplantation for adults with haematological malignancies: results from a single Australian centre. Intern Med J 2006; 36: 355-61.

[38] Schmitz N, Eapen M, Horowitz MM, et al. International Bone Marrow Transplant Registry; European Group for Blood and Marrow Transplantation. Long-term outcome of patients given transplants of mobilized blood or bone marrow: A report from the International Bone Marrow Transplant Registry and the European Group for Blood and Marrow Transplantation. Blood 2006; 108: 4288-90.

[39] Lemoli RM, Bandini G, Leopardi G, et al. Allogeneic peripheral blood stem cell transplantation in patients with early-phase hematologic malignancy: a retrospective comparison of short-term outcome with bone marrow transplantation. Haematologica 1998; 83: 48-55.

[40] Schetelig J, Bornhäuser M, Schmid C, et al. Matched unrelated or matched sibling donors result in comparable survival after allogeneic stem-cell transplantation in elderly patients with acute myeloid leukemia: a report from the cooperative German Transplant Study Group. J Clin Oncol 2008; 26: 5183-291.

[41] Fagioli F, Zecca M, Locatelli F, et al. AIEOP-HSCT group. Allogeneic stem cell transplantation for children with acute myeloid leukemia in second complete remission. J Pediatr Hematol Oncol 2008; 30: 575-83.

[42] Draper NL, Conley C, Smith C, Benson K. Dispermic chimerism identified during HLA typing for stem cell transplantation. Transfusion 2008; 48: 1398-402.

[43] Majhail NS, Brunstein CG, Tomblyn M, et al. Reduced-intensity allogeneic transplant in patients older than 55 years: unrelated umbilical cord blood is safe and effective for patients without a matched related donor. Biol Blood Marrow Transplant 2008; 14: 282-9.

[44] Dvorak CC, Agarwal R, Dahl GV, Gregory JJ, Feusner JH. Hematopoietic stem cell transplant for pediatric acute promyelocytic leukemia. Biol Blood Marrow Transplant 2008; 14: 824-30.

[45] Vigouroux S, Michallet M, Porcher R, et al. French Society of Bone Marrow Graft Transplantation and Cellular Therapy (SFGMTC). Long-term outcomes after reduced-intensity conditioning allogeneic stem cell transplantation for low-grade lymphoma: a survey by the French Society of Bone Marrow Graft Transplantation and Cellular Therapy (SFGM-TC). Haematologica 2007; 92: 62734.

[46] Vey N, Thomas X, Picard C, et al. GET-LALA Group the Swiss Group for Clinical Cancer Research (SAKK). Allogeneic stem cell 
transplantation improves the outcome of adults with $t(1 ; 19) / \mathrm{E} 2 \mathrm{~A}$ PBX1 and t(4;11)/MLL-AF4 positive B-cell acute lymphoblastic leukemia: results of the prospective multicenter LALA-94 study. Leukemia 2006; 20: 2155-61.

[47] Mahmoud H, Fahmy O, Kamel A, Kamel M, El-Haddad A, ElKadi D. Peripheral blood vs bone marrow as a source for allogeneic hematopoietic stem cell transplantation. Bone Marrow Transplant 1999; $24: 355-8$

[48] Oehler VG, Radich JP, Storer B, et al. Randomized trial of allogeneic related bone marrow transplantation versus peripheral blood stem cell transplantation for chronic myeloid leukemia. Biol Blood Marrow Transplant 2005; 11: 85-92.

[49] Reiffers J, Stoppa AM, Attal M, et al. Allogeneic vs autologous stem cell transplantation vs chemotherapy in patients with acute myeloid leukemia in first remission: the BGMT 87 study. Leukemia 1996; 10: 1874-82.

[50] Huff CA, Matsui W. Multiple myeloma cancer stem cells. J Clin Oncol 2008; 26: 2895-900.

[51] Parkin DM, Bray F, Ferlay J, Pisani P. Global cancer statistics, 2002. CA Cancer J Clin 2005; 55: 74-108.

[52] Merchionne F, Procaccio P, Dammacco F. Long-term survival in multiple myeloma: a single-center experience. Clin Exp Med 2008; 8: 133-9.

[53] van de Velde HJ, Liu X, Chen G, Cakana A, Deraedt W, Bayssas M. Complete response correlates with long-term survival and progression-free survival in high-dose therapy in multiple myeloma. Haematologica 2007; 92: 1399-406.

[54] Gahrton G, Tura S, Ljungman P, et al. Allogeneic bone marrow transplantation in multiple myeloma. European Group for Bone Marrow Transplantation. N Engl J Med 1991; 325: 1267-73.

[55] Attal M, Harousseau JL, Stoppa AM, et al. A prospective, randomized trial of autologous bone marrow transplantation and chemotherapy in multiple myeloma. Intergroupe Français du Myélome. N Engl J Med 1996; 335: 91-7.
[56] Child JA, Morgan GJ, Davies FE, et al. Medical Research Council Adult Leukaemia Working Party. High-dose chemotherapy with hematopoietic stem-cell rescue for multiple myeloma. $\mathrm{N}$ Engl $\mathrm{J}$ Med 2003; 348: 1875-83.

[57] Attal M, Harousseau JL, Facon T, et al. InterGroupe Francophone du Myélome. Single versus double autologous stem-cell transplan tation for multiple myeloma. N Engl J Med 2003; 349: 2495-502.

[58] Cavo M, Tosi P, Zamagni E, et al. Prospective, randomized study of single compared with double autologous stem-cell transplantation for multiple myeloma: Bologna 96 clinical study. J Clin Oncol 2007; 25: 2434-41.

[59] Henry JM, Sykes PJ, Brisco MJ, To LB, Juttner CA, Morley AA. Comparison of myeloma cell contamination of bone marrow and peripheral blood stem cell harvests. Br J Haematol 1996; 92: 614-9.

[60] Imrie K, Esmail R, Meyer RM. Members of the hematology disease site group of the cancer care ontario practice guidelines initiative. The role of high-dose chemotherapy and stem-cell transplantation in patients with multiple myeloma: a practice guideline of the Cancer Care Ontario Practice Guidelines Initiative. Ann Intern Med 2002; 136: 619-29.

[61] Compston JE. Bone marrow and bone: a functional unit. J Endocrinol 2002; 173: 387-94

[62] Schoemans H, Theunissen K, Maertens J, Boogaerts M, Verfaillie C, Wagner J. Adult umbilical cord blood transplantation: a comprehensive review. Bone Marrow Transplant 2006; 38: 83-93.

[63] O'Brien TA, Tiedemann K, Vowels MR. No longer a biological waste product: umbilical cord blood. Med J Aust 2006; 184: 407 10 .

[64] Hague SM, Klaffke S, Bandmann O. Neurodegenerative disorders: Parkinson's disease and Huntington's disease. J Neurol Neurosurg Psychiatry 2005; 76: 1058-63.

This is an open access article licensed under the terms of the Creative Commons Attribution Non-Commercial License (http://creativecommons.org/licenses/ by-nc/3.0/) which permits unrestricted, non-commercial use, distribution and reproduction in any medium, provided the work is properly cited. 